\title{
Palmitic acid increased yields of milk and milk fat and nutrient digestibility across production level of lactating cows
}

\author{
P. Piantoni, A. L. Lock, and M. S. Allen ${ }^{1}$ \\ Department of Animal Science, Michigan State University, East Lansing 48824
}

\begin{abstract}
The effects of palmitic acid supplementation on feed intake, digestibility, and metabolic and production responses were evaluated in dairy cows with a wide range of milk production (34.5 to $66.2 \mathrm{~kg} / \mathrm{d}$ ) in a crossover design experiment with a covariate period. Thirty-two multiparous Holstein cows $(151 \pm 66 \mathrm{~d}$ in milk) were randomly assigned to treatment sequence within level of milk production. Treatments were diets supplemented (2\% of diet DM) with palmitic acid (PA; 99\% C16:0) or control (SH; soyhulls). Treatment periods were $21 \mathrm{~d}$, with the final $4 \mathrm{~d}$ used for data and sample collection. Immediately before the first treatment period, cows were fed the control diet for $21 \mathrm{~d}$ and baseline values were obtained for all variables (covariate period). Milk production measured during the covariate period (preliminary milk yield) was used as covariate. In general, no interactions were detected between treatment and preliminary milk yield for the response variables measured. The PA treatment increased milk fat percentage (3.40 vs. $3.29 \%)$ and yields of milk (46.0 vs. $44.9 \mathrm{~kg} / \mathrm{d})$, milk fat (1.53 vs. $1.45 \mathrm{~kg} / \mathrm{d})$, and $3.5 \%$ fat-corrected milk (44.6 vs. $42.9 \mathrm{~kg} / \mathrm{d}$ ), compared with $\mathrm{SH}$. Concentrations and yields of protein and lactose were not affected by treatment. The PA treatment did not affect dry matter (DM) intake or body weight, tended to decrease body condition score (2.93 vs. 2.99), and increased feed efficiency (3.5\% fat-corrected milk/ DM intake; 1.60 vs. 1.54), compared with SH. The PA treatment increased total-tract digestibility of neutral detergent fiber (39.0 vs. 35.7\%) and organic matter (67.9 vs. $66.2 \%)$, but decreased fatty acid (FA) digestibility (61.2 vs. $71.3 \%$ ). As total FA intake increased, total FA digestibility decreased $\left(\mathrm{R}^{2}=0.51\right)$ and total FA absorbed increased (quadratic $\mathrm{R}^{2}=0.82$ ). Fatty acid yield response, calculated as the additional FA yield secreted in milk per unit of additional FA intake, was $11.7 \%$ for total FA and $16.5 \%$ for C16:0 plus cis-9 C16:1 FA. The PA treatment increased plasma concen-
\end{abstract}

Received February 9, 2013.

Accepted July 8, 2013.

${ }^{1}$ Corresponding author: allenm@msu.edu tration of nonesterified FA (101 vs. $90.0 \mu \mathrm{Eq} / \mathrm{L})$ and cholecystokinin (19.7 vs. $17.6 \mathrm{pmol} / \mathrm{L})$, and tended to increase plasma concentration of insulin (10.7 vs. 9.57 $\mu \mathrm{IU} / \mathrm{mL})$. Results show that palmitic acid fed at $2 \%$ of diet DM has the potential to increase yields of milk and milk fat, independent of production level without increasing body condition score or body weight. However, a small percentage of the supplemented FA was partitioned to milk.

Key words: palmitic acid, production level, milk fat, fat supplementation

\section{INTRODUCTION}

Long-chain saturated fat supplements have been used to increase the energy density of diets (Wang et al., 2010) and milk fat yield (Steele and Moore, 1968; Steele, 1969; Wang et al., 2010) in dairy cows and have been reported to increase feed efficiency (Wang et al., 2010; Lock et al., 2013) and milk yield (Steele, 1969; Enjalbert et al., 2000). Moreover, they are considered to be inert in the rumen (Grummer, 1988; Schauff and Clark, 1989), and have little effect on DMI (Allen, 2000) and nutrient digestibility (Grummer, 1988; Schauff and Clark, 1989; Elliott et al., 1996). However, production responses to highly saturated fats ( $>85 \%$ saturated) have varied greatly. For instance, supplementation of a highly saturated fat fed at 1.5 to $2 \%$ of diet DM had various effects on productive performance compared with a control diet with no fat added: increasing milk yield by $3.1 \mathrm{~kg} / \mathrm{d}$ (Mosley et al., 2007) and $2.2 \mathrm{~kg} / \mathrm{d}$ (Wang et al., 2010), or not affecting milk yield (Lock et al., 2013); increasing fat yield by $286 \mathrm{~g} / \mathrm{d}$ (Mosley et al., 2007) and $90 \mathrm{~g} / \mathrm{d}$ (Lock et al., 2013), or not affecting fat yield (Warntjes et al., 2008); and increasing DMI by $3.1 \mathrm{~kg} / \mathrm{d}$ (Mosley et al., 2007), not affecting DMI (Wang et al., 2010), or decreasing DMI by $1.4 \mathrm{~kg} / \mathrm{d}$ (Lock et al., 2013).

Variability across experiments could be due to the level of milk production of the cows used. Harvatine and Allen (2005) showed that milk protein yield was increased to a greater extent for high-producing cows than lower-producing cows for saturated compared with unsaturated FA supplements. Furthermore, early- 
lactation cows with lower milk yield responded more favorably to the dietary inclusion of a highly saturated fat supplement than cows with higher milk production in a field study (Warntjes et al., 2008). Variability across experiments could also be related to the use of different types of fat supplements and rates of feeding. Fat supplements vary in FA chain lengths and degree of esterification and in their feeding rates, which vary widely from less than $2 \%$ (Wang et al., 2010) to greater than $5 \%$ of diet DM (Mosley et al., 2007) across experiments. In addition, the substitution method might also affect production responses if the supplement is added in place of a source of glucose precursors such as corn (Wang et al., 2010), a fermentable fiber source such as soyhulls (Lock et al., 2013), or the base diet (Mosley et al., 2007). Because of inconsistent responses to feeding saturated fats, it is currently not clear when these supplements should be fed and whether their use can increase production and feed efficiency of cows and profitability of dairy farms.

To identify the effects of specific FA on dairy cow performance, studies involving the use of pure FA are required. Palmitic acid is an SFA that is commonly found in many different saturated fat supplements and dairy cow feedstuffs. Although several studies have been reported with fat sources containing approximately $85 \%$ palmitic acid, the remaining FA might have influenced responses to treatment, so studies with pure FA are required. Steele and Moore (1968) evaluated a pure (96\%) palmitic acid supplement on production responses for cows in mid lactation but the milk yield of the cows was low $(\sim 12 \mathrm{~kg} / \mathrm{d})$ and responses measured were limited. To our knowledge, no studies exist that have evaluated the effects of supplementation of a pure palmitic acid supplement on digestion and metabolic and production responses in lactating dairy cows or how responses vary with level of milk production. The objectives of this experiment were to evaluate the effects of palmitic acid supplementation and its interaction with level of milk production on digestion, metabolism, and production of lactating dairy cows. We hypothesized that a palmitic acid-enriched supplement compared with soyhulls would increase milk yield, milk fat yield, and feed efficiency of dairy cows and that responses would differ across production levels.

\section{MATERIALS AND METHODS}

\section{Animal Housing and Care}

All experimental procedures were approved by the Institutional Animal Care and Use Committee at Michigan State University (East Lansing). All cows were housed in the same tie-stall throughout the entire experiment. Cows were fed once daily (0800 h) at $110 \%$ of expected intake and milked twice daily (0400 and $1500 \mathrm{~h}$ ). The amounts of feed offered and orts were weighed for each cow daily.

\section{Design and Treatment Diets}

Thirty-two multiparous Holstein cows $(151 \pm 66$ DIM; mean \pm SD) at the Michigan State University Dairy Field Laboratory were used in a crossover design experiment with a covariate period. Cows were selected from the herd to provide a uniform distribution and a wide range of milk yield ( 34.5 to $66.2 \mathrm{~kg} / \mathrm{d}$ ). Cows were randomly assigned to treatment sequence within levels of milk production varying by approximately $5 \mathrm{~kg} / \mathrm{d}$. The experiment was $63 \mathrm{~d}$ in duration and consisted of a 21-d preliminary (covariate) period and two 21-d treatment periods. During the preliminary period, cows were fed the control diet and baseline values were obtained for all variables (Table 1). During the first treatment period, half of the cows were fed the control diet (SH) with no supplemental fat added, whereas the remaining cows were fed the palmitic acid-supplemented diet (PA; prilled FFA supplement: 99\% C16:0; Emery Oleochemicals, Selangor, Malaysia). The palmitic acid supplement was added at $2 \%$ of diet DM, replacing $2 \%$ of soyhulls in the control diet. Diets were switched for the second treatment period. The ingredient and nutrient composition of the diets fed as TMR are described in Table 2. Diets were formulated to meet requirements of the average cow in the group according to NRC (2001).

\section{Data and Sample Collection}

Samples and data were collected during the last $4 \mathrm{~d}$ of the second week of the covariate period (d 11 to 15) and during the last $4 \mathrm{~d}$ of each treatment period (d 18 to 21$)$. Samples of all diet ingredients $(0.5 \mathrm{~kg})$ and orts from each cow (12.5\%) were collected daily and composited by period. Milk yield was recorded and 2 milk samples were collected at each milking. One milk sample was stored without preservative at $-20^{\circ} \mathrm{C}$ for determination of FA profile and the other was stored with preservative at $4^{\circ} \mathrm{C}$ for component analysis (Universal Lab Services, East Lansing, MI). Fecal (500 g) and blood samples $(\sim 15 \mathrm{~mL})$ were collected every 15 $\mathrm{h}$, resulting in 8 samples per cow per period, representing every $3 \mathrm{~h}$ of a 24 -h period to account for diurnal variation. Feces were stored in a sealed plastic cup at $-20^{\circ} \mathrm{C}$ until dried. Blood was collected by coccygeal venipuncture into 3 evacuated tubes; 2 contained potassium EDTA as an anticoagulant and the other contained potassium oxalate as an anticoagulant and 
Table 1. Baseline data for cows used in this study, obtained during the preliminary period when cows were fed a common $\operatorname{diet}(\mathrm{n}=32)$

\begin{tabular}{|c|c|c|c|c|}
\hline Parameter & Mean & SD & Minimum & Maximum \\
\hline \multicolumn{5}{|l|}{ Yield, kg/d } \\
\hline Milk & 48.3 & 9.39 & 31.3 & 64.6 \\
\hline Fat & 1.49 & 0.31 & 0.72 & 2.14 \\
\hline Protein & 1.46 & 0.22 & 1.01 & 1.84 \\
\hline Lactose & 2.34 & 0.49 & 1.46 & 3.17 \\
\hline $3.5 \% \mathrm{FCM}$ & 45.1 & 8.04 & 30.3 & 60.0 \\
\hline ECM & 45.5 & 7.69 & 31.7 & 59.1 \\
\hline \multicolumn{5}{|l|}{ Milk composition, $\%$} \\
\hline Fat & 3.14 & 0.58 & 1.68 & 4.05 \\
\hline Protein & 3.05 & 0.20 & 2.73 & 3.71 \\
\hline Lactose & 4.83 & 0.16 & 4.36 & 5.08 \\
\hline $\mathrm{SCC}, \times 1,000 / \mathrm{mL}$ & 44.5 & 77.4 & 1.93 & 363 \\
\hline DMI, kg & 28.0 & 3.34 & 20.9 & 34.3 \\
\hline $3.5 \%$ FCM/DMI & 1.61 & 0.18 & 1.30 & 2.01 \\
\hline $\mathrm{BW}, \mathrm{kg}$ & 702 & 74.6 & 556 & 902 \\
\hline $\mathrm{BCS}$ & 2.90 & 0.81 & 1.92 & 4.67 \\
\hline \multicolumn{5}{|l|}{ Total-tract digestibility, $\%$} \\
\hline DM & 62.5 & 3.04 & 56.1 & 68.3 \\
\hline $\mathrm{OM}$ & 64.8 & 2.86 & 59.1 & 70.1 \\
\hline $\mathrm{NDF}$ & 36.2 & 6.24 & 22.6 & 49.1 \\
\hline $\mathrm{CP}$ & 61.9 & 3.82 & 53.3 & 66.5 \\
\hline Starch & 96.2 & 0.95 & 93.6 & 98.2 \\
\hline \multicolumn{5}{|l|}{ Plasma metabolites and hormones } \\
\hline Insulin, $\mu \mathrm{IU} / \mathrm{mL}$ & 11.1 & 4.40 & 4.08 & 24.8 \\
\hline Glucagon, pg/mL & 147 & 16.9 & 114 & 191 \\
\hline Insulin:glucagon ratio & 0.076 & 0.030 & 0.027 & 0.165 \\
\hline Glucose, $\mathrm{mg} / \mathrm{dL}$ & 55.9 & 2.55 & 52.0 & 63.0 \\
\hline $\mathrm{NEFA}, \mu \mathrm{Eq} / \mathrm{L}$ & 107 & 21.4 & 82.2 & 155.9 \\
\hline Triglyceride, mg/dL & 9.77 & 1.22 & 7.31 & 12.7 \\
\hline \multicolumn{5}{|l|}{ Glucose tolerance test } \\
\hline Glucose baseline, mg/dL & 59.9 & 2.65 & 55.4 & 67.5 \\
\hline Maximum glucose, ${ }^{1} \mathrm{mg} / \mathrm{dL}$ & 232 & 64.5 & 170 & 430 \\
\hline Glucose area under the curve ${ }^{1}$ & 421 & 83.8 & 274 & 601 \\
\hline Insulin baseline, $\mu \mathrm{IU} / \mathrm{mL}$ & 4.04 & 1.44 & 3.05 & 9.53 \\
\hline Maximum insulin, ${ }^{1} \mu \mathrm{IU} / \mathrm{mL}$ & 44.8 & 16.3 & 19.8 & 89.8 \\
\hline Insulin area under the curve ${ }^{1}$ & 118 & 51.8 & 26.8 & 248 \\
\hline \multicolumn{5}{|l|}{ Insulin tolerance test } \\
\hline Glucose baseline, mg/dL & 59.2 & 3.05 & 54.1 & 64.8 \\
\hline Minimum glucose, mg/dL & 40.1 & 5.82 & 21.5 & 48.6 \\
\hline Glucose area under the curve & -115 & 50.2 & -249 & -26.8 \\
\hline Insulin baseline, $\mu \mathrm{IU} / \mathrm{mL}$ & 3.72 & 1.24 & 3.01 & 8.86 \\
\hline Maximum insulin, ${ }^{1} \mu \mathrm{IU} / \mathrm{mL}$ & 325 & 306 & 76.0 & 1,446 \\
\hline Insulin area under the curve ${ }^{1}$ & 528 & 342 & 217 & 1,650 \\
\hline
\end{tabular}

${ }^{1} \mathrm{n}=31$.

sodium fluoride as a glycolytic inhibitor. Blood was stored on ice until centrifugation at $2,000 \times g$ for 15 min at $4^{\circ} \mathrm{C}$ (within 30 min of sample collection). Two aliquots $(1 \mathrm{~mL})$ of plasma from the potassium EDTA tube were stored in $0.05 M$ benzamidine (final concentration) to prevent enzymatic degradation of glucagon or cholecystokinin (CCK). The remaining plasma was transferred into microcentrifuge tubes and stored at $-20^{\circ} \mathrm{C}$ until composited by cow by period. Body weight and BCS were recorded at the end of each period. Body condition was scored by 3 trained investigators on a 5 -point scale, where $1=$ thin and $5=$ fat (in 0.25-point increments), as described by Wildman et al. (1982).

\section{Glucose and Insulin Tolerance Tests}

Glucose and insulin tolerance tests were performed during the last week of the covariate period to further characterize the physiological state of individual cows. Cows were divided into 2 groups of 16 cows each for catheterization and tolerance tests to provide a 2-d resting period between procedures. The glucose tolerance test (GTT) was conducted according to Bradford and Allen (2007) on d 18 and 19 and the insulin tolerance test (ITT) was conducted according to Smith et al. (2007) on d 20 and 21. All cows were fitted with a single jugular catheter $2 \mathrm{~d}$ before the GTT. Indwelling 14 -gauge $\times 13$-cm radiopaque polyurethane extended- 
Table 2. Ingredient and nutrient composition of the treatment $\operatorname{diets}^{1}$

\begin{tabular}{lcc}
\hline & \multicolumn{2}{c}{ Diet } \\
\cline { 2 - 3 } Item & SH & PA \\
\hline Ingredient, \% of DM & & \\
Corn silage & 25.8 & 25.8 \\
Alfalfa silage & 7.33 & 7.34 \\
Chopped alfalfa hay & 6.23 & 6.23 \\
Dry ground corn & 31.2 & 31.2 \\
Soybean meal & 12.5 & 12.5 \\
Soyhulls & 9.20 & 7.19 \\
Cottonseed with lint & 3.64 & 3.64 \\
Vitamin-mineral mix ${ }^{2}$ & 4.18 & 4.18 \\
Palmitic acid supplement (99\% C16:0) & 0.00 & 1.98 \\
Nutrient composition & & \\
DM, \% & 62.0 & 62.1 \\
OM, \% of DM & 93.4 & 93.5 \\
NDF, \% of DM & 30.4 & 29.1 \\
\% Forage NDF & 19.1 & 19.1 \\
\% NDF from forage & 62.7 & 65.5 \\
iNDF, \% of DM & 9.51 & 9.40 \\
CP, \% of DM & 15.9 & 15.7 \\
Starch, \% of DM & 29.3 & 29.2 \\
Total FA, \% of DM & 2.52 & 4.47 \\
C16:0, \% of DM & 0.464 & 2.41 \\
\hline
\end{tabular}

${ }^{1}$ Treatments were either control (SH; with $2 \%$ of diet DM as added soyhulls) or a palmitic acid-supplemented diet (PA; with $2 \%$ of diet DM as palmitic acid; $99 \%$ C16:0).

${ }^{2}$ Vitamin-mineral mix contained (DM basis) $30.1 \%$ limestone, $25.3 \%$ sodium bicarbonate, $10.1 \%$ salt-white, $7.07 \%$ urea, $6.00 \%$ potassium chloride, $5.98 \%$ dicalcium phosphate, $5.68 \%$ magnesium sulfate, $5.68 \%$ animal fat, $3.94 \%$ trace mineral premix and vitamins, $0.21 \%$ selenium yeast $600(600 \mathrm{mg}$ of $\mathrm{Se} / \mathrm{kg})$.

${ }^{3}$ Indigestible NDF.

use catheters were used for infusions and blood collection. Catheter patency was checked daily with $10 \mathrm{~mL}$ of heparinized saline (20 IU of heparin $/ \mathrm{mL}$ of saline) until removed after the ITT. On the day of the GTT and ITT, cows were blocked from feed at $0730 \mathrm{~h}$ and not allowed access until the tests were completed. For the GTT, a sterile solution of $50 \%$ dextrose (wt/vol) was administered by intrajugular bolus at a dose of $1.67 \mathrm{mmol}$ of glucose $/ \mathrm{kg}$ of BW within $8 \mathrm{~min}$. For the ITT, insulin (product no. I5500; Sigma-Aldrich, St. Louis, MO) was infused at a dose of $1.2 \mu \mathrm{g}$ of insulin/ $\mathrm{kg}$ of BW within $1 \mathrm{~min}$. Catheters were flushed with 5 to $10 \mathrm{~mL}$ of heparinized saline (4 IU of heparin/mL of saline) after infusions and after blood collections. Samples were processed as described above, within $1 \mathrm{~h}$ of collection.

\section{Sample Analysis}

Feed, orts, and fecal samples were dried in a $55^{\circ} \mathrm{C}$ forced-air oven for $72 \mathrm{~h}$ and analyzed for DM concentration. All samples were ground in a Wiley mill (1-mm screen; Arthur H Thomas Co., Philadelphia, PA) and analyzed for ash, NDF, indigestible NDF, CP, starch, and FA. Feces were composited on an equal DM basis by cow by period before analysis. All nutrients are expressed as percentages of DM, determined by drying at $105^{\circ} \mathrm{C}$ in a forced-air oven for more than $8 \mathrm{~h}$. Ash concentration was determined after $5 \mathrm{~h}$ of oxidation at $500^{\circ} \mathrm{C}$. Concentration of NDF was determined according to Mertens (2002). Indigestible NDF, which was used as an internal marker to estimate fecal output and nutrient digestibility (Cochran et al., 1986), was estimated as NDF residue after $240 \mathrm{~h}$ in vitro fermentation (Goering and Van Soest, 1970); flasks were reinoculated at $120 \mathrm{~h}$ to ensure a viable microbial population. Ruminal fluid for the in vitro incubations was collected from a nonpregnant dry cow fed dry hay only. Crude protein was determined according to Hach et al. (1987). Starch was gelatinized with sodium hydroxide and hydrolyzed using an enzymatic method (Karkalas, 1985); glucose was then measured using a glucose oxidase method (PGO Enzyme Product No. P7119; Sigma Chemical Co., St. Louis, MO) and by determination of absorbance with a microplate reader (SpectraMax 190; Molecular Devices Corp., Sunnyvale, CA). Fatty acids from feed ingredients and orts were determined using a one-step transesterification method, according to Sukhija and Palmquist (1988). Briefly, $1 \mathrm{mg}$ of cis-10 C17:1, diluted in acetone, was added to the oven-dried ground samples (sample weight chosen to provide 10 to $50 \mathrm{mg}$ of FA) to calculate total FA yield. Fatty acid methyl esters (FAME) were then prepared by adding 2 $\mathrm{mL}$ of $5 \%$ methanolic sulfuric acid to the samples. After samples were incubated overnight at $50^{\circ} \mathrm{C}$, they were allowed to cool down and neutralized with a $5 \%$ sodium chloride solution. Fatty acids from feces were extracted with a 2-step methylation procedure, as described by Jenkins (2010). An internal standard (cis-10 C17:1) was added to the oven-dried ground fecal samples as described above for feed ingredients and orts. Fatty acid methyl esters from feed ingredients, orts, and feces were extracted with hexane and filtered through silica gel and charcoal. Hexane was evaporated under $\mathrm{N}_{2}$ at $30^{\circ} \mathrm{C}$, FAME were weighed, and samples reconstituted in hexane to obtain a $1 \%$ solution. Fatty acid methyl esters were quantified by gas-liquid chromatography (GC-2010 Plus; Shimadzu Corp., Kyoto, Japan), using a CP-8827 WCOT fused silica column (30-m long $\times 0.32$ $\mathrm{mm}$ i.d. $\times 0.025-\mu \mathrm{m}$ film thickness; Varian Inc., Lake Forest, CA). The chromatograph was equipped with a split injector (1:100 split ratio) and a flame-ionization detector. Hydrogen was used as the carrier gas at a flow rate of $1 \mathrm{~mL} / \mathrm{min}$ and for the flame-ionization detector at $40 \mathrm{~mL} / \mathrm{min}$. Purified air was used at a flow rate of $400 \mathrm{~mL} / \mathrm{min}$ and nitrogen makeup gas at $30 \mathrm{~mL} / \mathrm{min}$. Injector and detector temperatures were kept at $270^{\circ} \mathrm{C}$. Initially, the oven temperature was $140^{\circ} \mathrm{C}$ for $1 \mathrm{~min}$, after which it was increased by $5^{\circ} \mathrm{C} / \min$ to $225^{\circ} \mathrm{C}$ and 
then by $50^{\circ} \mathrm{C} / \mathrm{min}$ to $250^{\circ} \mathrm{C}$, and held for $5.5 \mathrm{~min}$. The injection volume was $1 \mu \mathrm{L}$ of FAME-hexane mixture. Integration was performed with GCsolution software (version 2.32.00; Shimadzu Corp.). Fatty acid methyl esters were identified by comparison of retention times with known FAME standards (GLC 63A and GLC 455 from Nu-Chek Prep Inc., Elysian, MN).

All plasma samples were analyzed in duplicate, unless otherwise specified. Commercial kits were used to determine plasma concentrations of NEFA [NEFA-HR (2) kit; Wako Chemicals USA Inc., Richmond, VA; intraassay CV: $2.5 \%$, interassay CV: $3.1 \%$ ], triglyceride (L-Type Triglyceride M kit; Wako Chemicals USA Inc.; intraassay CV: $14.6 \%$, interassay CV: $8.8 \%$ ), insulin (Coat-A-Count RIA kit; Siemens Healthcare Diagnostics, Deerfield, IL; intraassay CV: 7.8\%), glucagon (Glucagon RIA kit no. GL-32K; Millipore Corp., St. Charles, MA; intraassay CV: 4.4\%), and CCK (EuriaCCK kit no. RB 302 US; Euro Diagnostica, Malmö, Sweden; singlicate analysis; intraassay CV: 3\%). Plasma glucose concentration was analyzed using a glucose oxidase method (PGO Enzyme Product No. P7119; Sigma Chemical Co.; intraassay CV: 1.1\%, interassay CV: $1.0 \%)$.

Milk samples stored with preservative were analyzed for fat, true protein, lactose, MUN, and SCC by infrared spectroscopy (AOAC International, 1997), by the Michigan Herd Improvement Association (Universal Lab Services). Milk samples stored without preservative were composited by milk fat yield and centrifuged at $17,800 \times g$ for $30 \mathrm{~min}$ at $4^{\circ} \mathrm{C}$ to collect the fat cake. Lipids were extracted according to Hara and Radin (1978) and FAME prepared according to Christie (1989). Quantification of FAME using gas-liquid chromatography was performed as described by Caldari-Torres et al. (2011). A total of approximately 80 individual FA were quantified per sample. Even though all quantified FA were used for summation by source and concentration calculations, only select FA were included in the tables. Yield of individual FA in milk fat were calculated by correcting for glycerol content according to Schauff et al. (1992), and other milk lipid classes according to Glasser et al. (2007). The FA yield response (FAYR) to additional FA intake was calculated for total FA and for C16:0 plus cis-9 C16:1 with the following equation:

$$
\text { FAYR }(\%)=(\text { FA yield for PA }- \text { FA yield for SH }) /
$$

$$
\text { (FA intake for PA - FA intake for } \mathrm{SH} \text { ). }
$$

\section{Statistical Analysis}

All data were analyzed using the fit model procedure of JMP (version 9.0.2; SAS Institute, Cary, NC) according to the following model:

$$
\begin{aligned}
& Y_{i j k}=\mu+C_{i}+P_{j}+T_{k}+P_{j} \times T_{k}+p M Y+p M Y \\
& \times T_{k}+p M Y \times p M Y+p M Y \times p M Y \times T_{k}+e_{i j k},
\end{aligned}
$$

where $\mathrm{Y}_{\mathrm{ijk}}=$ dependent variable, $\mu=$ overall mean, $\mathrm{C}_{\mathrm{i}}$ $=$ random effect of cow $(\mathrm{i}=1$ to 32$), \mathrm{P}_{\mathrm{j}}=$ fixed effect of period ( $\mathrm{j}=1$ to 2$), \mathrm{T}_{\mathrm{k}}=$ fixed effect of treatment $(\mathrm{k}=1$ to 2$), \mathrm{pMY}=$ preliminary milk yield used as covariate, $\mathrm{pMY} \times \mathrm{T}_{\mathrm{k}}=$ interaction between $\mathrm{pMY}$ and treatment, $\mathrm{pMY} \times \mathrm{pMY}=\mathrm{pMY}$ squared, $\mathrm{pMY} \times \mathrm{pMY} \times \mathrm{T}_{\mathrm{k}}=$ interaction between $\mathrm{pMY} \times \mathrm{pMY}$ and treatment, and $\mathrm{e}_{\mathrm{ijk}}=$ residual error. Linear and quadratic effects for the interaction between pMY and treatment were added to evaluate responses to treatment by level of milk yield. Normality of the residuals was checked with normal probability and box plots and homogeneity of variances with plots of residuals versus predicted values. When necessary, data was transformed and this was noted in the tables. Main effects were declared significant at $P \leq 0.05$, and tendencies were declared at $P \leq 0.10$. Interactions were declared significant at $P \leq 0.10$, and tendencies were declared at $P \leq 0.15$. Interactions were evaluated, but removed from the statistical model when not significant $(P>0.15)$. In general, period by treatment interaction was not significant, but variables with significant interactions are noted in the tables. All data were expressed as least squares means and standard error of the means, unless otherwise specified.

\section{RESULTS}

\section{Production Responses}

Treatment did not interact with preliminary milk yield for any production response measured (Table $3)$. The PA treatment increased milk fat percent (3.40 vs. $3.27 \% ; P=0.01)$ and yields of milk (46.0 vs. 44.9 $\mathrm{kg} / \mathrm{d} ; P<0.05)$ and milk fat $(1.53$ vs. $1.45 \mathrm{~kg} / \mathrm{d} ; P$ $<0.01$ ). Concentrations and yields of protein, lactose, solids, SNF, and MUN were not affected by treatment. The PA treatment increased $3.5 \%$ FCM yield by 1.74 $\mathrm{kg} / \mathrm{d}$ and ECM yield by $1.57 \mathrm{~kg} / \mathrm{d}$ (both $P<0.01$ ) because of the increases in both milk yield and milk fat percentage. The PA treatment did not affect DMI or BW, tended to decrease BCS slightly $(P=0.06)$, and increased feed efficiency (3.5\% FCM/DMI) by 0.06 units $(P<0.01)$.

\section{Total-Tract Digestibility}

Treatment did not interact with preliminary milk production for total-tract digestibility of any feed fraction measured, except for 16-carbon FA (Table 4). The PA treatment increased DM and OM total-tract digestibility by 2.8 and $2.6 \%$, respectively (both $P<$ 
Table 3. Dry matter intake, milk production and composition, BW, and BCS for cows fed treatment diets $(\mathrm{n}=32)$

\begin{tabular}{|c|c|c|c|c|c|}
\hline Item & \multicolumn{2}{|c|}{$\operatorname{Trt}^{1}$} & SEM & \multicolumn{2}{|c|}{ Significance, $P$-value } \\
\hline \multicolumn{5}{|l|}{ Yield, $\mathrm{kg} / \mathrm{d}$} & 0.84 \\
\hline Milk & 44.9 & 46.0 & 1.74 & 0.04 & 0.87 \\
\hline Fat & 1.45 & 1.53 & 0.05 & 0.001 & 0.45 \\
\hline Protein & 1.38 & 1.41 & 0.04 & 0.13 & 0.84 \\
\hline $3.5 \% \mathrm{FCM} / \mathrm{DMI}$ & 1.54 & 1.60 & 0.03 & $<0.0001$ & 0.73 \\
\hline \multicolumn{6}{|l|}{ Milk composition, $\%$} \\
\hline Fat & 3.29 & 3.40 & 0.11 & 0.01 & 0.50 \\
\hline Protein & 3.11 & 3.09 & 0.05 & 0.57 & 0.98 \\
\hline Lactose & 4.85 & 4.82 & 0.03 & 0.28 & 0.17 \\
\hline $\mathrm{SCC}, \times 1,000 / \mathrm{mL}$ & 36.5 & 43.6 & 11.6 & 0.48 & 0.25 \\
\hline
\end{tabular}

${ }^{1}$ Trt $=$ dietary treatment. Treatments were either control (SH; with $2 \%$ of diet DM as added soyhulls) or a palmitic acid-supplemented diet (PA; with $2 \%$ of diet DM as palmitic acid; $99 \%$ C16:0).

0.01), mainly from higher NDF digestibility, which increased by $9.2 \%(P<0.001)$, and $\mathrm{CP}$ digestibility, which increased by $3.3 \%(P<0.05)$. A treatment by period interaction was detected for $\mathrm{CP}$ digestibility $(P$ $=0.07) ; \mathrm{PA}$ increased $\mathrm{CP}$ digestibility substantially during period 1 (65.1 vs. $61.2 \pm 0.87 \%$ ), but not during period 2 (67.9 vs. $67.6 \pm 0.87 \%)$. In contrast, PA did not affect digestibility of starch and decreased total FA digestibility by $14.2 \%(P<0.001)$. Moreover, PA decreased 16-carbon FA digestibility by $25.7 \%(P<$ $0.001)$ and increased 18-carbon FA digestibility slightly $(P=0.02)$ compared with SH. The interaction between preliminary milk yield and treatment for 16-carbon FA digestibility indicated that cows with higher milk yield had lower 16-carbon FA digestibility than cows with lower milk yield during the preliminary period (interaction $P=0.07)$. Further, total FA digestibility decreased as total FA intake increased $\left(\mathrm{R}^{2}=0.51 ; P<0.0001\right.$; Figure 1).

As expected, PA increased intakes of total FA and 16-carbon FA by $551 \mathrm{~g} / \mathrm{d}$ (both $P<0.0001$; Table 5 ). The interaction between preliminary milk yield and treatment for the intakes of total FA and 16-carbon FA (both $P<0.01$ ) indicated that the difference in intakes for cows with lower milk production was slightly less than for cows with higher milk production. Intake of 18 -carbon FA was not affected by diet $(P=0.75)$. The PA treatment increased absorption of total FA and 16-carbon FA by 262 and $250 \mathrm{~g} / \mathrm{d}$, respectively (both $P<0.0001$; Table 5), and tended to increase absorption of 18 -carbon FA by $10 \mathrm{~g} / \mathrm{d}(P=0.10)$. Total FA absorption increased at a decreasing rate as total FA intake increased (quadratic $\mathrm{R}^{2}=0.82 ; P=0.01$; Figure 2). An interaction between treatment and period

Table 4. Total-tract digestibility for cows fed treatment diets $(\mathrm{n}=32)$

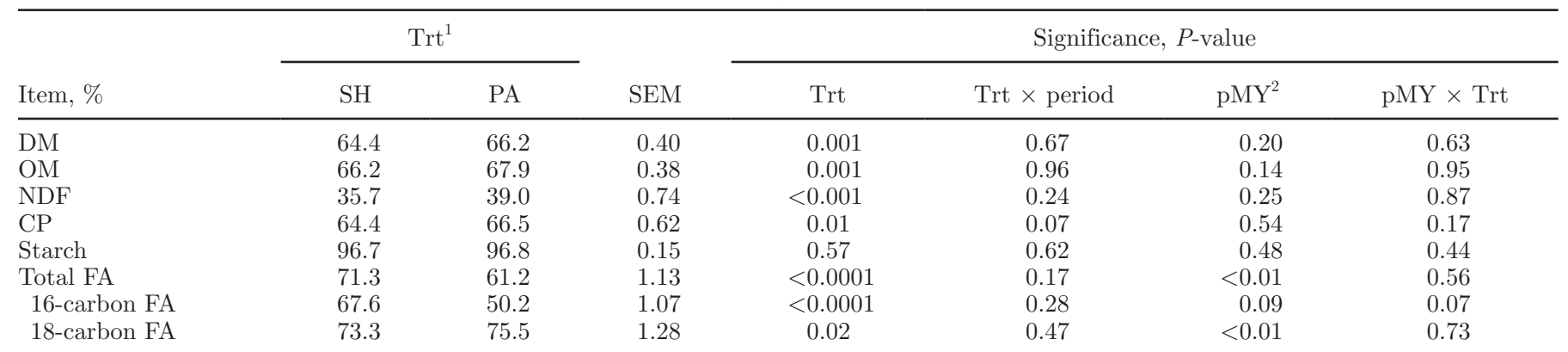

${ }^{1}$ Trt $=$ dietary treatment. Treatments were either control (SH; with $2 \%$ of diet DM as added soyhulls) or a palmitic acid-supplemented diet (PA; with $2 \%$ of diet DM as palmitic acid; $99 \%$ C16:0).

${ }^{2} \mathrm{pMY}=$ preliminary milk yield. 


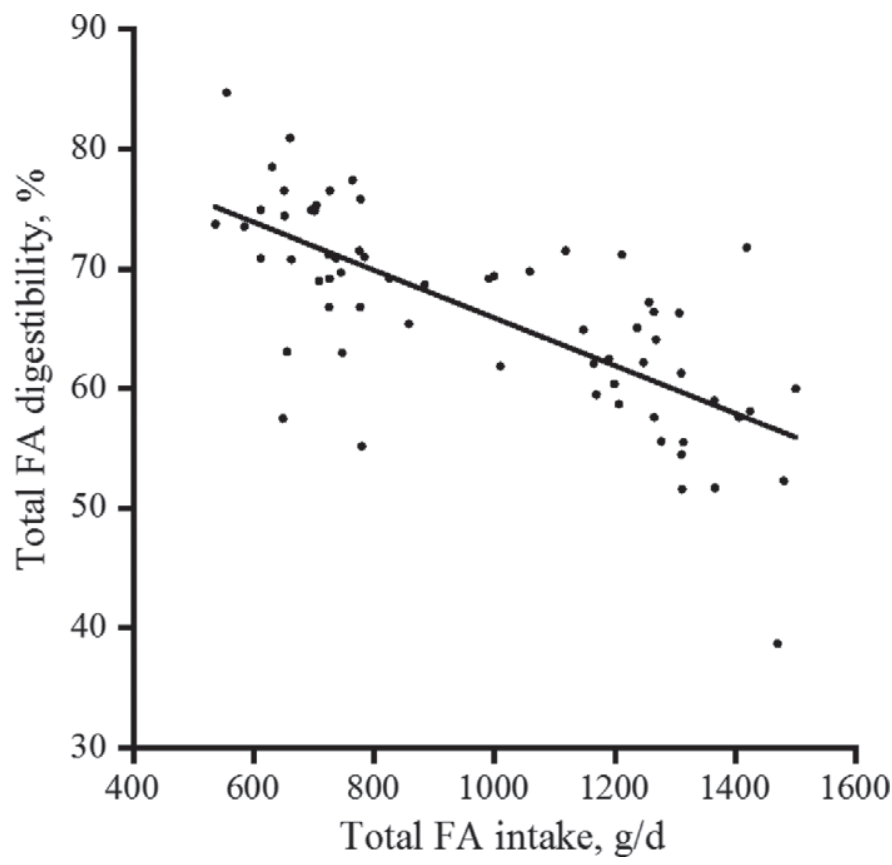

Figure 1. Relationship between total FA digestibility and total FA intake of cows fed treatment diets [total FA digestibility $(\%)=85.9-$ $0.020 \times$ total FA intake $\left.(\mathrm{g} / \mathrm{d}) ; \mathrm{R}^{2}=0.51 ; P<0.0001\right]$. Cows with FA intakes higher than $950 \mathrm{~g} / \mathrm{d}$ were on the palmitic acid-supplemented diet $(\mathrm{n}=32)$, whereas cows with FA intakes lower than $950 \mathrm{~g} / \mathrm{d}$ were on the control diet $(\mathrm{n}=32)$.

was detected for total FA absorption $(P=0.05)$; PA increased total FA absorbed by $216 \mathrm{~g} / \mathrm{d}$ during period 1 , but by $308 \mathrm{~g} / \mathrm{d}$ during period 2 . A similar interaction between treatment and period was observed for 16-carbon FA absorption $(P=0.001)$.

\section{Plasma Metabolites and Hormones}

Treatment did not interact with preliminary milk yield for plasma concentration of any hormone or metabolite, except glucagon (Table 6). The PA treatment

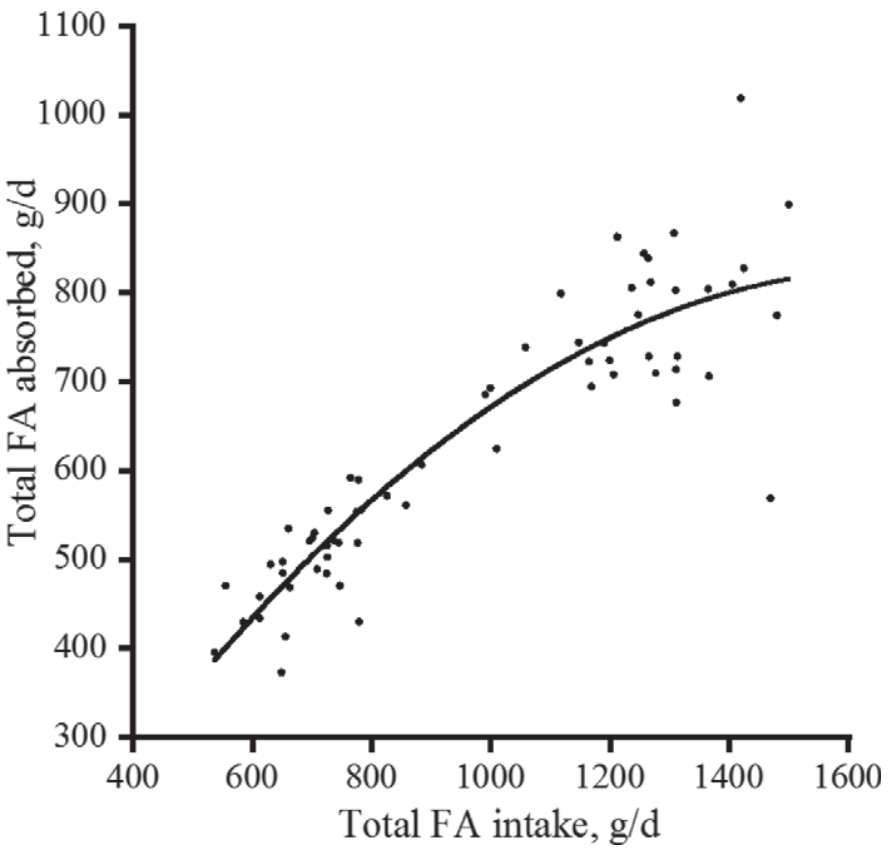

Figure 2. Relationship between total FA absorbed and total FA intake of cows fed treatment diets $\{$ total FA absorbed $(\mathrm{g} / \mathrm{d})=202+$ $0.470 \times$ total FA intake $(\mathrm{g} / \mathrm{d})-0.0003 \times[\text { FA intake }(\mathrm{g} / \mathrm{d})-983]^{2} ; \mathrm{R}^{2}$ $=0.82 ; P=0.01\}$. Cows with FA intakes higher than $950 \mathrm{~g} / \mathrm{d}$ were on the palmitic acid-supplemented diet $(\mathrm{n}=32)$, whereas cows with FA intakes lower than $950 \mathrm{~g} / \mathrm{d}$ were on the control diet $(\mathrm{n}=32)$.

decreased plasma glucagon concentration compared with $\mathrm{SH}$ (interaction $P=0.07$ ) for cows with preliminary milk yield greater than $55 \mathrm{~kg} / \mathrm{d}$ only (data not shown). Although PA did not affect plasma glucose concentration, it tended to increase plasma insulin concentration by $11.7 \%(P=0.06)$ and insulin-toglucagon ratio by $9.6 \%(P=0.07)$. The PA treatment also increased plasma CCK concentration by $11.9 \%(P$ $<0.001$ ). Plasma triglyceride concentration was not affected by treatment, but PA increased plasma NEFA concentration by $12.7 \%(P<0.001)$.

Table 5. Total FA intake and absorbed for cows fed treatment diets $(\mathrm{n}=32)$

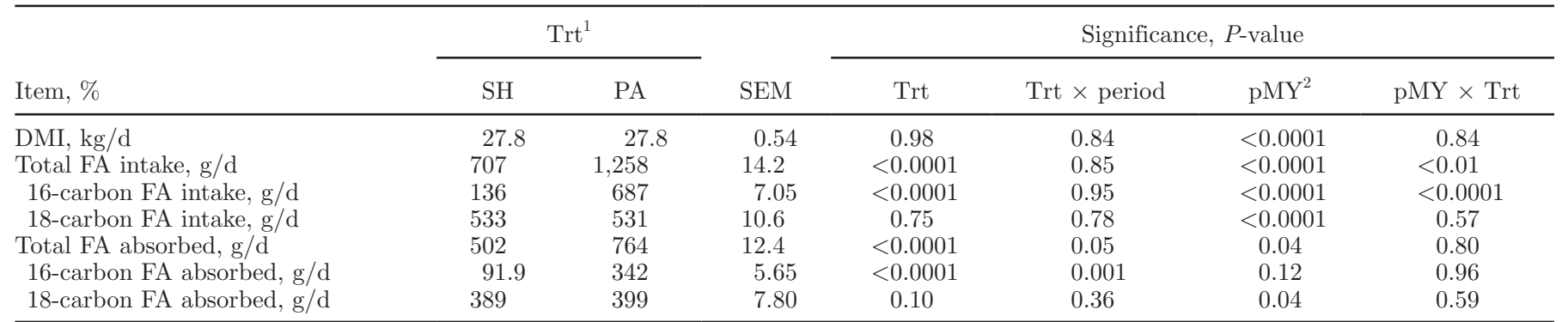

${ }^{1} \mathrm{Trt}=$ dietary treatment. Treatments were either control (SH; with $2 \%$ of diet DM as added soyhulls) or a palmitic acid-supplemented diet (PA; with $2 \%$ of diet DM as palmitic acid; $99 \%$ C16:0).

${ }^{2} \mathrm{pMY}=$ preliminary milk yield. 
Table 6. Plasma metabolites and hormones of cows fed treatment diets $(\mathrm{n}=32)$

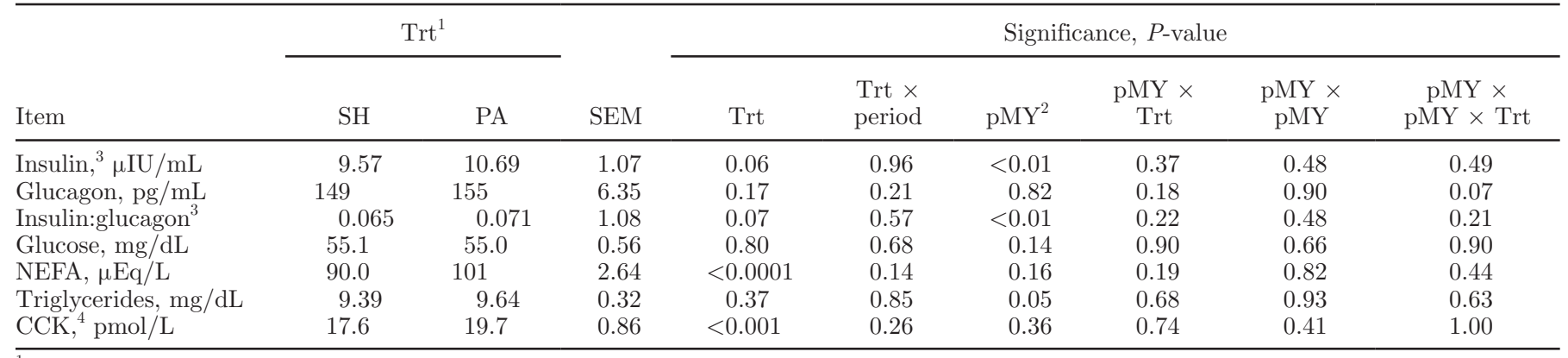

${ }^{1}$ Trt = dietary treatment. Treatments were either control (SH; with $2 \%$ of diet DM as added soyhulls) or a palmitic acid-supplemented diet (PA; with $2 \%$ of diet DM as palmitic acid; $99 \%$ C16:0).

${ }^{2} \mathrm{pMY}=$ preliminary milk yield.

${ }^{3}$ Data were transformed $\left(\log _{10}\right)$ before analysis to meet the assumption of homogeneity of variance. For interpretation purposes, means and SEM were back-transformed and included in the table.

${ }^{4}$ Cholecystokinin.

\section{Milk FA Profile and Yields}

The PA treatment increased concentrations of mixed source FA in milk, but decreased concentrations of de novo and preformed FA $(P<0.001$; Table 7$)$. Mixedsource FA (C16:0 plus cis-9 C16:1) can originate from both preformed (dietary or mobilized) and de novo synthesis in the mammary gland (Bauman and Griinari, 2003). Interactions between treatment and preliminary milk yield with respect to the concentrations of preformed and mixed-source FA indicate that treatment affected cows differently depending on their level of milk production; for cows with higher milk production, the difference in concentrations of preformed and mixed-source FA between diets was less than for cows with lower milk production (both $P<0.15$ ).

No interactions were observed between treatment and preliminary milk yield for yields of individual FA in milk (Table 8). The PA treatment increased yields of mixed source FA in milk (564 vs. $473 \mathrm{~g} / \mathrm{d} ; P<0.0001$ ) and PA decreased slightly the yield of de novo FA (395 vs. $408 \mathrm{~g} / \mathrm{d} ; P=0.05)$ and did not affect yields of preformed FA.

\section{FAYR to Additional FA Intake}

No interactions were detected between treatment and preliminary milk production for FAYR to the additional FA intake when calculated for either total FA or for C16:0 plus cis-9 C16:1. For each additional $100 \mathrm{~g}$ intake of total FA, milk FA increased by $11.7 \mathrm{~g}$ compared with SH. When only C16:0 plus cis-9 C16:1 were considered, for each additional $100 \mathrm{~g}$ intake of these FA, C16:0 plus cis-9 C16:1 increased by $16.5 \mathrm{~g}$ compared with SH.

\section{DISCUSSION}

Previous research on saturated fat supplementation suggests that cows at different levels of milk production can respond differently to a treatment diet (Harvatine and Allen, 2005; Warntjes et al., 2008). However, all cows in this study responded similarly to palmitic acid supplementation, as evidenced by a lack of interaction between treatment and preliminary milk production for almost every response variable measured. Exceptions were plasma glucagon concentration, 16-carbon FA digestibility, total FA intake, 16-carbon FA intake, and profiles of several individual milk FA. Interactions between treatment and preliminary milk yield for these variables were small and likely not biologically important. Preliminary milk yield was used as a covariate, because this information is readily available to the dairy producer and, therefore, can easily be used for grouping and feeding cows. Glucose tolerance test and ITT results were added to the statistical model and evaluated as possible covariates, but interactions with treatment were not significant (data not shown).

Palmitic acid supplementation did not affect DMI, but increased milk yield, which, together with an increase in milk fat concentration, resulted in an increase in $3.5 \%$ FCM yield. The lack of an effect on DMI and the increase in 3.5\% FCM yield resulted in a slight increase in feed efficiency. Steele (1969) reported that a supplement high in palmitic acid ( 85\% C16:0) fed at approximately $4.25 \%$ of diet DM increased milk yield by $1 \mathrm{~kg} / \mathrm{d}$, milk fat yield by $115 \mathrm{~g} / \mathrm{d}$, and milk fat percentage by $13 \%$, when compared with a nonsupplemented control diet. Moreover, palmitic acid supplementation decreased milk protein concentration by $6.4 \%$ without affecting milk protein yield and increased milk lactose 
Table 7. Milk FA concentrations ${ }^{1}$ of cows fed treatment diets $(\mathrm{n}=32)$

\begin{tabular}{|c|c|c|c|c|c|c|c|}
\hline Item, g/100 g & \multicolumn{2}{|c|}{$\operatorname{Trt}^{2}$} & SEM & \multicolumn{4}{|c|}{ Significance, $P$-value } \\
\hline \multicolumn{8}{|c|}{ Summation by source ${ }^{4}$} \\
\hline Mixed & 34.7 & 39.4 & 0.33 & $<0.0001$ & 0.11 & 0.03 & 0.03 \\
\hline Preformed & 35.4 & 33.1 & 0.43 & $<0.0001$ & 0.81 & 0.01 & 0.10 \\
\hline \multicolumn{8}{|c|}{ Selected individual FA } \\
\hline $8: 0$ & 1.31 & 1.21 & 0.03 & $<0.0001$ & 0.02 & 0.48 & 0.91 \\
\hline 10:0 & 3.43 & 3.10 & 0.07 & $<0.0001$ & 0.06 & 0.67 & 0.72 \\
\hline $12: 0$ & 4.11 & 3.68 & 0.08 & $<0.0001$ & 0.20 & 0.94 & 0.54 \\
\hline $14: 0$ & 12.4 & 11.3 & 0.13 & $<0.0001$ & 0.83 & 0.18 & 0.64 \\
\hline cis-9 14:1 & 0.962 & 0.920 & 0.04 & $<0.0001$ & 0.27 & 0.45 & 0.93 \\
\hline $16: 0$ & 33.0 & 37.6 & 0.34 & $<0.0001$ & 0.23 & 0.04 & 0.03 \\
\hline cis-9 16:1 & 1.66 & 1.80 & 0.06 & $<0.0001$ & 0.05 & 0.90 & 0.23 \\
\hline
\end{tabular}

${ }^{1}$ A total of approximately 80 individual FA were quantified and used for calculations (summation by source and concentrations). Only select FA are reported in the table.

${ }^{2}$ Trt $=$ dietary treatment. Treatments were either control (SH; with $2 \%$ of diet DM as added soyhulls) or a palmitic acid-supplemented diet (PA; with $2 \%$ of diet DM as palmitic acid; $99 \%$ C16:0).

${ }^{3} \mathrm{pMY}=$ preliminary milk yield.

${ }^{4}$ De novo FA originate from mammary de novo synthesis ( $<16$ carbons), preformed FA originate from extraction from plasma ( $>16$ carbons), and mixed FA originate from both sources (C16:0 plus cis-9 C16:1).

${ }^{5}$ Total 18:1 trans FA.

yield by $8.6 \%$ with no effect on lactose concentration (Steele, 1969). In the present experiment, PA did not affect milk protein concentration or lactose yield de- spite increased yields of milk and milk fat, consistent with results reported by Steele (1969). More recently, and consistent with our results, a FA supplement high

Table 8. Milk FA yields ${ }^{1}$ of cows fed treatment diets $(\mathrm{n}=32)$

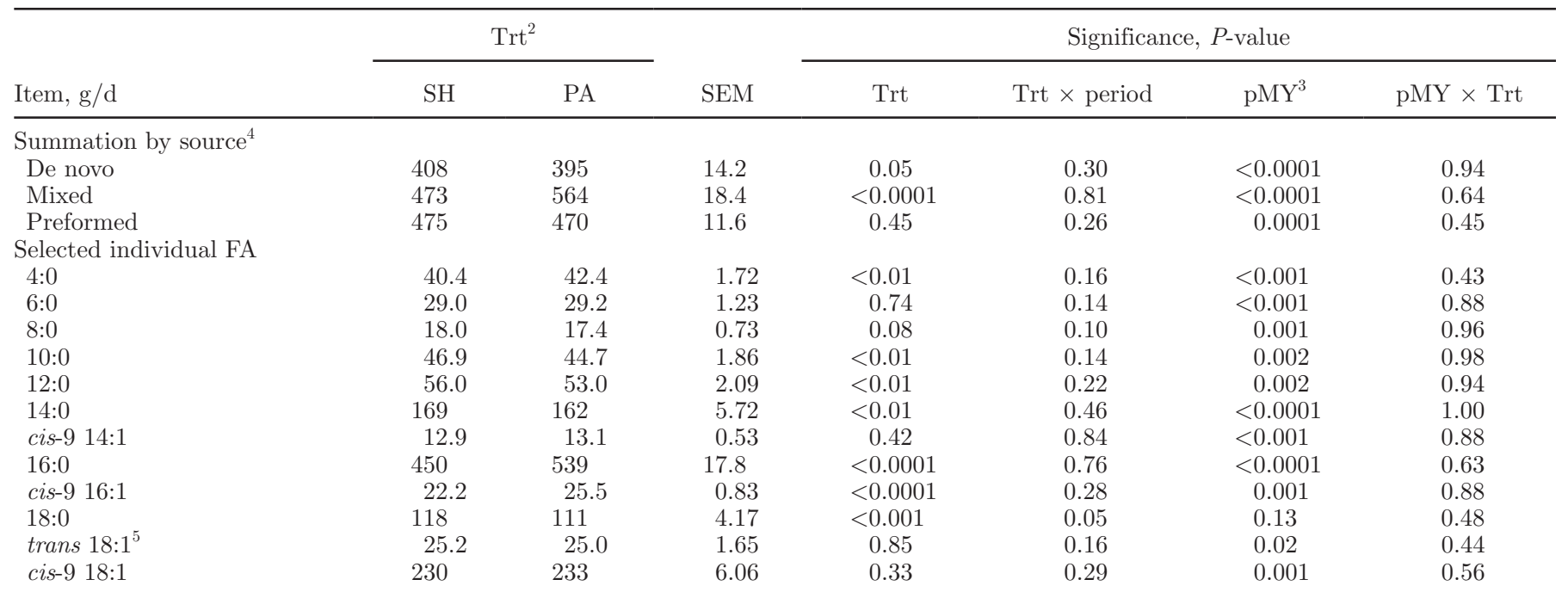

${ }^{1} \mathrm{~A}$ total of approximately 80 individual FA were quantified and used for calculations (summation by source). Only select FA are reported in the table.

${ }^{2}$ Trt $=$ dietary treatments. Treatments were either control ( $\mathrm{SH}$; with $2 \%$ of diet DM as added soyhulls) or a palmitic acid-supplemented diet (PA; with $2 \%$ of diet DM as palmitic acid; $99 \%$ C16:0).

${ }^{3} \mathrm{pMY}=$ preliminary milk yield.

${ }^{4}$ De novo FA originate from mammary de novo synthesis ( $<16$ carbons), preformed FA originate from extraction from plasma ( $>16$ carbons), and mixed FA originate from both sources (C16:0 plus cis-9 C16:1).

${ }^{5}$ Total 18:1 trans FA. 
in palmitic acid ( $\sim 85 \%)$ fed at $2 \%$ of diet DM increased milk fat yield by $90 \mathrm{~g} / \mathrm{d}$ and $3.5 \%$ FCM by $1.5 \mathrm{~kg} / \mathrm{d}$ as well as increased feed efficiency (Lock et al., 2013). The increase in feed efficiency was a result of increased $3.5 \% \mathrm{FCM}$ and a decrease in DMI of $1.4 \mathrm{~kg} / \mathrm{d}$, which was not observed in the current study. As DMI was not affected by PA, the milk yield response observed could be because of an increase in energy consumed per day from the FA supplementation, because of higher OM digestibility, or both. In addition, the increase in milk fat percentage and yield observed for PA is likely directly related to the higher level of palmitic acid in the experimental diet, which raised plasma NEFA, but not triglyceride concentration. Saturated fat addition to diets has previously been reported to increase plasma concentrations of NEFA and triglycerides (Choi et al., 2000). Kronfeld (1965) showed that a plasma NEFA concentration higher than $300 \mu \mathrm{Eq} / \mathrm{L}$ was associated with increased milk fat output in fresh cows. However, in our study, plasma NEFA was only one-third of that threshold and PA increased NEFA by only $12.7 \%$. The NEFA concentration we observed may have been related to the higher FA intake as well as to an increased mobilization of body fat reserves related the slight decrease in BCS observed for PA $(P$ $=0.06)$. The PA treatment tended to increase insulin concentration, consistent with the effects of dietary saturated fat supplementation for cows (Harvatine and Allen, 2006) and rats (Stein et al., 1997). Increased insulin concentration is expected to decrease lipolysis, which is inconsistent with the tendency for the decrease in BCS observed. The increase in concentration and yield of milk fat could also be explained by a longer retention time of digesta in the rumen, consistent with the increase in NDF digestibility and CCK concentration observed, which could favor a more complete biohydrogenation of conjugated linoleic acid isomers associated with milk fat depression in dairy cows (e.g., trans-10,cis-12 C18:2; Bauman et al., 2011). These biohydrogenation intermediates decrease milk fat synthesis in the mammary gland (Baumgard et al., 2002), but have opposite effects in adipose tissue (Harvatine et al., 2009). Nevertheless, we did not find evidence of lower concentrations in milk of previously described FA isomers related to milk fat depression (data not shown) and, therefore, this explanation for the increased milk fat yield observed is speculative. A decrease in the concentration of currently unknown bioactive FA isomers could explain both the increase in milk fat production and the tendency for the change in BCS observed when PA was fed in our study.

The effect of palmitic acid supplementation on milk FA yields was consistent with that observed by Steele and Moore (1968) in regard to a slight decrease in de novo FA $(<16$-carbon FA) synthesis and an increase in C16:0 in milk, but not with the decrease in preformed FA (>16-carbon FA) in milk. In agreement with Lock et al. (2013), we did not see an effect of palmitic acid on preformed FA yields. The FAYR was only $11.7 \%$ for total FA and $16.5 \%$ for C16:0 plus cis-9 C16:1 FA. Because the average intake of 16-carbon FA for PA was approximately 5 times higher than $\mathrm{SH}$, the low FAYR to palmitic acid supplementation could not be explained by decreased FA digestibility alone. Similarly, a transfer efficiency of $16.5 \%$, calculated as the fraction of digested C16:0 partitioned to milk, was reported previously in a field study where an approximately $85 \%$ palmitic acid supplement was fed at $450 \mathrm{~g} / \mathrm{d}$ (Warntjes et al., 2008). The authors suggested that this low transfer efficiency was related to oxidation of the FA as metabolic fuel rather than export as milk triglycerides. In contrast, a higher FAYR (46.7\%), calculated as the additional C16:0 consumed and partitioned to milk relative to control, has been reported when $490 \mathrm{~g}$ of palmitic acid was infused in the duodenum (Enjalbert et al., 2000). In our study, increased milk fat yield was accounted for by the increase in total 16-carbon FA in milk.

Saturated FA generally do not affect DMI when added to diets at normal inclusion rates (up to $3 \%$ of total DM; Palmquist and Jenkins, 1980). Allen (2000) showed that DMI was not affected by hydrogenated FA in a meta-analysis of 29 treatment means reported in the literature. Consistent with this, we did not detect a difference in DMI between treatments in the present study. Results are inconsistent, however, for studies in which highly enriched $(\geq 85 \%)$ sources of palmitic acid were supplemented; supplementation of an enriched palmitic acid supplement decreased DMI (Lock et al., 2013) but also increased DMI (Mosley et al., 2007) compared with a control diet with no supplemental fat when supplemented at $500 \mathrm{~g} / \mathrm{d}$.

In general, supplementation of saturated fats has not affected OM digestibility. Although saturated fat supplementation did not affect nutrient digestibility in several studies (Schauff and Clark, 1989; Grum et al., 1996; Harvatine and Allen, 2006), a highly enriched palmitic acid supplement tended to increase digestibility for several nutrient fractions in a field study (Warntjes et al. 2008). However, no previous experiment has measured digestibility responses to a pure palmitic acid supplement. The increase in nutrient digestibility observed in the present study might have been caused by an increase in ruminal retention time, possibly from a reduction in rumen motility from increased plasma CCK concentration, which has previously been reported when saturated fats were fed (Choi et al., 2000). An increased ruminal retention time might decrease passage of FA biohydrogenation intermediates (e.g., conjugated 
linoleic acid) to the duodenum, previously mentioned as one of the possibilities for increased milk fat yield.

Studies from our laboratory (Harvatine and Allen, 2006) and others (Wu et al., 1993; Elliott et al., 1996; Grum et al., 1996) have reported decreased FA digestibility when SFA were fed. Palmquist (1991) showed a reduction in FA digestibility as FA intake increased, consistent with our results. Furthermore, total FA absorption increased at a decreasing rate with greater total FA intake. Decreased FA digestibility and absorption at high FA intakes might be related to excessive amounts of FA reaching the small intestine (Palmquist, 1991). Alternative explanations are an alteration of the micelle formation in the duodenum or biliary salts production in response to increased proportions of saturated versus unsaturated FA (Doreau and Chilliard, 1997). Nevertheless, neither of these hypotheses has been tested. We only report total FA and 16- and 18-carbon FA in feces because of the biohydrogenation of unsaturated FA that occurs in the rumen and large intestine that can lead to overestimation of unsaturated FA digestibility and underestimation of SFA digestibility.

Because milk income is primarily dependent on protein and fat yields in most markets, dietary FA supplements have the potential to increase profitability of dairy farms. Increased profitability would depend on the cost of the supplement relative to other diet ingredients, the value of the production and feed efficiency responses in relation to milk price, and other intangibles related to reproduction and health. All of these factors need to be considered to determine the feasibility of the utilization of any dietary supplement in dairy herds. In the present study, palmitic acid substituted for soyhulls increased milk fat yield by 80 $\mathrm{g} / \mathrm{d}$, and did not affect milk protein yield or DMI. In view of these results, producers would have to consider only the slight increase in milk fat yield to evaluate whether it is profitable to feed a similar supplement to their herds. Research using highly enriched palmitic acid supplements has often reported increases in milk fat yield and various responses in terms of DMI, and therefore feed efficiency. For these reasons, their use on dairy farms might be justifiable in some cases, but the marginal return on any such supplement must be carefully considered.

\section{CONCLUSIONS}

Our results confirmed our hypothesis that palmitic acid supplementation compared with soyhulls can increase milk yield, milk fat yield, and feed efficiency of dairy cows. However, production responses to palmitic acid did not differ across the production level of cows.
Further studies are required to evaluate the effects on performance of other long-chain SFA, such as stearic acid, interactions of FA supplements with other dietary components, and to understand the reasons for differences in DMI and FAYR across studies with palmitic acid supplements.

\section{ACKNOWLEDGMENTS}

We acknowledge the Malaysian Palm Oil Board (Selangor, Malaysia) for financial support of this research and T. Tompkins and Milk Specialties Global for supplying the palmitic acid supplement. We also thank D. G. Main, R. A. Longuski, C. Preseault, S. E. Stocks, W. Brown, R. Rockwell, K. Kammes, R. E. Kreft (all from Michigan State University) and the staff of the Michigan State University Dairy Cattle Field Laboratory (East Lansing) for their assistance in this experiment.

\section{REFERENCES}

Allen, M. S. 2000. Effects of diet on short-term regulation of feed intake by lactating dairy cattle. J. Dairy Sci. 83:1598-1624.

AOAC International. 1997. Official Methods of Analysis. 16th ed. AOAC International Gaithersburg, MD.

Bauman, D. E., and J. M. Griinari. 2003. Nutritional regulation of milk fat synthesis. Annu. Rev. Nutr. 23:203-227.

Bauman, D. E., K. J. Harvatine, and A. L. Lock. 2011. Nutrigenomics, rumen-derived bioactive fatty acids, and the regulation of milk fat synthesis. Annu. Rev. Nutr. 31:299-319.

Baumgard, L. H., B. A. Corl, D. A. Dwyer, and D. E. Bauman. 2002. Effects of conjugated linoleic acids (CLA) on tissue response to homeostatic signals and plasma variables associated with lipid metabolism in lactating dairy cows. J. Anim. Sci. 80:1285-1293.

Bradford, B. J., and M. S. Allen. 2007. Depression in feed intake by a highly fermentable diet is related to plasma insulin concentration and insulin response to glucose infusion. J. Dairy Sci. 90:3838 3845 .

Caldari-Torres, C., A. L. Lock, C. R. Staples, and L. Badinga. 2011. Performance, metabolic, and endocrine responses of periparturient Holstein cows fed 3 sources of fat. J. Dairy Sci. 94:1500-1510.

Choi, B.-R, D. L. Palmquist, and M. S. Allen. 2000. Cholecystokinin mediates depression of feed intake in dairy cattle fed high fat diets. Domest. Anim. Endocrinol. 19:159-175.

Christie, W. W. 1989. Gas Chromatography and Lipids: A Practical Guide. The Oily Press, Ayr, Scotland.

Cochran, R. C., D. C. Adams, J. D. Wallace, and M. L. Galyean. 1986. Predicting the digestibility of different diets with internal markers: Evaluation of four potential markers. J. Anim. Sci. 63:1476-1483.

Doreau, M., and Y. Chilliard. 1997. Digestion and metabolism of dietary fat in farm animals. Br. J. Nutr. 78(Suppl. 1):S15-S35.

Elliott, J. P., J. K. Drackley, and D. J. Weigel. 1996. Digestibility and effects of hydrogenated palm fatty acid distillate in lactating dairy cows. J. Dairy Sci. 79:1031-1039.

Enjalbert, F., M. C. Nicot, C. Bayourthe, and R. Moncoulon. 2000 Effects of duodenal infusions of palmitic, stearic, or oleic acids on milk composition and physical properties of butter. J. Dairy Sci. 83:1428-1433.

Glasser, F., M. Doreau, A. Ferlay, and Y. Chilliard. 2007. Technical note: Estimation of milk fatty acid yield from milk fat data. J. Dairy Sci. 90:2302-2304.

Goering, H. K., and P. J. Van Soest. 1970. Forage Fiber Analysis (Apparatus, Reagents, Procedures, and Some Applications). Ag- 
ricultural Handbook no. 379. US Department of Agriculture-Agricultural Research Service (USDA-ARS), Washington, DC.

Grum, D. E., J. K. Drackley, L. R. Hansen, and J. D. Cremin Jr. 1996. Production, digestion, and hepatic lipid metabolism of dairy cows fed increased energy from fat or concentrate. J. Dairy Sci. 79:1836-1849.

Grummer, R. R. 1988. Influence of prilled fat and calcium salt of palm oil fatty acids on ruminal fermentation and nutrient digestibility. J. Dairy Sci. 71:117-123.

Hach, C. C., B. K. Bowden, A. B. Kopelove, and S. V. Brayton. 1987. More powerful peroxide Kjeldahl digestion method. J. Assoc. Off. Anal. Chem. 70:783-787.

Hara, A., and N. S. Radin. 1978. Lipid extraction of tissues with a low-toxicity solvent. Anal. Biochem. 90:420-426.

Harvatine, K. J., and M. S. Allen. 2005. The effect of production level on feed intake, milk yield, and endocrine responses to two fatty acid supplements in lactating cows. J. Dairy Sci. 88:4018-4027.

Harvatine, K. J., and M. S. Allen. 2006. Effects of fatty acid supplements on ruminal and total tract nutrient digestion in lactating dairy cows. J. Dairy Sci. 89:1092-1103.

Harvatine, K. J., J. W. Perfield, and D. E. Bauman. 2009. Expression of enzymes and key regulators of lipid synthesis is upregulated in adipose tissue during CLA-induced milk fat depression in dairy cows. J. Nutr. 139:849-854.

Jenkins, T. C. 2010. Technical note: Common analytical errors yielding inaccurate results during analysis of fatty acids in feed and digesta samples. J. Dairy Sci. 93:1170-1174.

Karkalas, J. 1985. An improved enzymic method for the determination of native and modified starch. J. Sci. Food Agric. 36:1019-1027.

Kronfeld, D. S. 1965. Plasma non-esterified fatty acid concentrations in dairy cows: Responses to nutritional and hormonal stimuli, and significance in ketosis. Vet. Rec. 77:30-35.

Lock, A. L., C. L. Preseault, J. E. Rico, K. E. DeLand, and M. S. Allen. 2013. Feeding a C16:0-enriched fat supplement increased the yield of milk fat and improved feed efficiency. J. Dairy Sci. 96:6650-6659. http://dx.doi.org/10.3168/jds.2013-6892.

Mertens, D. R. 2002. Gravimetric determination of amylase-treated neutral detergent fiber in feeds using refluxing in beakers or crucibles: Collaborative study. J. AOAC Int. 85:1217-1240.

Mosley, S. A., E. E. Mosley, B. Hatch, J. I. Szasz, A. Corato, N. Zacharias, D. Howes, and M. A. McGuire. 2007. Effect of varying levels of fatty acids from palm oil on feed intake and milk production in Holstein cows. J. Dairy Sci. 90:987-993.

NRC. 2001. Nutrient Requirements of Dairy Cattle. 7th rev. ed. National Academy of Sciences, Washington, DC.
Palmquist, D. L. 1991. Influence of source and amount of dietary fat on digestibility in lactating cows. J. Dairy Sci. 74:1354-1360.

Palmquist, D. L., and T. C. Jenkins. 1980. Fat in lactation rations: Review. J. Dairy Sci. 63:1-14.

Schauff, D. J., and J. H. Clark. 1989. Effects of prilled fatty acids and calcium salts of fatty acids on rumen fermentation, nutrient digestibilities, milk production, and milk composition. J. Dairy Sci. 72:917-927.

Schauff, D. J., J. P. Elliott, J. H. Clark, and J. K. Drackley. 1992 Effects of feeding lactating dairy cows diets containing whole soybeans and tallow. J. Dairy Sci. 75:1923-1935.

Smith, K. L., S. E. Stebulis, M. R. Waldron, and T. R. Overton. 2007. Prepartum 2,4-thiazolidinedione alters metabolic dynamics and dry matter intake of dairy cows. J. Dairy Sci. 90:3660-3670.

Steele, W. 1969. The effects of dietary palmitic and stearic acids on milk yield and composition in the cow. J. Dairy Res. 36:369-373.

Steele, W., and J. H. Moore. 1968. The effects of a series of saturated fatty acids in the diet on milk-fat secretion in the cow. J. Dairy Res. 35:361-370.

Stein, D. T., B. E. Stevenson, M. W. Chester, M. Basit, M. B. Daniels, S. D. Turley, and J. D. McGarry. 1997. The insulinotropic potency of fatty acids is influenced profoundly by their chain length and degree of saturation. J. Clin. Invest. 100:398-403.

Sukhija, P. S., and D. L. Palmquist. 1988. Rapid method for determination of total fatty acid content and composition of feedstuffs and feces. J. Agric. Food Chem. 36:1202-1206.

Wang, J. P., D. P. Bu, J. Q. Wang, X. K. Huo, T. J. Guo, H. Y. Wei, L. Y. Zhou, R. R. Rastani, L. H. Baumgard, and F. D. Li. 2010. Effect of saturated fatty acid supplementation on production and metabolism indices in heat-stressed mid-lactation dairy cows. J Dairy Sci. 93:4121-4127.

Warntjes, J., P. Robinson, E. Galo, E. DePeters, and D. Howes. 2008 Effects of feeding supplemental palmitic acid (C16:0) on performance and milk fatty acid profile of lactating dairy cows under summer heat. Anim. Feed Sci. Technol. 140:241-257.

Wildman, E. E., G. M. Jones, P. E. Wagner, R. L. Boman, H. F. Troutt Jr., and T. N. Lesch. 1982. A dairy cow body condition scoring system and its relationship to selected production characteristics. J. Dairy Sci. 65:495-501.

Wu, Z., J. T. Huber, F. T. Sleiman, J. M. Simas, K. H. Chen, S. C. Chan, and C. Fontes. 1993. Effect of three supplemental fat sources on lactation and digestion in dairy cows. J. Dairy Sci. $76: 3562-3570$ 